\title{
Crisis de incorporación en América Latina: límites de la modernización conservadora*
}

\author{
Fernando Filgueira, Luis Reygadas, Juan Pablo Luna y Pablo \\ Alegre** $^{* *}$
}

\begin{abstract}
Resumen
Este texto analiza la crisis de incorporación que se produjo en América Latina al finalizar el siglo XX, como consecuencia de la combinación de cambios en el modelo de desarrollo, durabilidad de las democracias electorales, persistencia de las desigualdades e incremento de expectativas relacionadas con la movilidad educativa y la difusión de nuevos patrones de consumo. Este tipo de crisis ocurren cuando la necesidad de interacción cooperativa en los mercados y en la política, así como la presión social en términos de demandas económicas, políticas y sociales no están siendo atendidas por los patrones institucionales de incorporación y regulación. Argumentaremos que se trata de un cambio de época, caracterizado como un proceso de modernización conservadora, cuyas tensiones y limitaciones ayudan a explicar el giro hacia la izquierda en la primera década del siglo XXI.
\end{abstract}

\begin{abstract}
This article explores the incorporation crisis that occurred in Latin America at the end of the twentieth century as a result of: changes in the economic model, the durability of electoral democracies and of inequalities; increasing expectations related to educational mobility, and the dissemination of new patterns of consumption. It is argued that this type of crisis can be best understood as an epochal change of "conservative modernization". It is also argued that this change is at the basis of the shift to the Left in present day Latin America.
\end{abstract}

Palabras clave: modernización conservadora, crisis de incorporación, izquierda, desigualdad, políticas sociales, calidad de la democracia.

Key words: Latin America, conservative modernization, incorporation crisis, partisanship, inequality, social policies, quality of democracy.

* Este artículo está dedicado a la memoria de Pablo Alegre, joven académico uruguayo fallecido en 2009, quien participó en la redacción de las primeras versiones de este texto. Pablo fue primero estudiante y luego colega y amigo cercano de Fernando Filgueira y Juan Pablo Luna. A pesar de lo prematuro de su muerte, Pablo deja un amplio legado en lo académico y en lo personal. Su infinita bondad, su lucidez intelectual y su persistente compromiso con proyectos de investigación rigurosos, pero social y políticamente relevantes, continúan siendo una fuente de inspiración permanente para quienes tuvimos el privilegio de conocerlo.

** Fernando Filgueira es doctor en sociología de Northwestern University y es oficial de asuntos sociales de la División de Estudios Sociales de la CEPAL en Santiago de Chile. Luis Reygadas es doctor en ciencias antropológicas por la Universidad Autónoma Metropolitana y profesor del Departamento de Antropología de la Universidad Autónoma Metropolitana Unidad Iztapalapa, México. Juan Pablo Luna es doctor en ciencia política por la Universidad de North Carolina en Chapel Hill y es profesor de la Pontificia Universidad Católica de Chile; su colaboración en este texto fue posible gracias al financiamiento recibido por parte del Proyecto Núcleo Milenio NS 100014 y del Proyecto Fondecyt 1110565. Pablo Alegre tiene una licenciatura en ciencias sociales por la Universidad Católica del Uruguay. 


\section{Una gran transformación y una respuesta incipiente}

a obra clásica de Karl Polanyi, La gran transformación (1944), resuena en América Latina en los años posteriores a la caída de los regímenes autoritarios y el fin del modelo de industrialización por sustitución de importaciones (ISI). Para muchos académicos esta transformación ha sido eminentemente política; para otros, básicamente económica. En este trabajo tomaremos una visión más amplia: una perspectiva que abarcará las transformaciones políticas, económicas y sociales desde el punto de vista particular de la teoría sociológica clásica. Queremos ver estas transformaciones como expresiones y motores del cambio en los patrones de interacción y comportamiento, así como en las expectativas y actitudes de la población. Esta perspectiva también busca entender la dinámica política como una respuesta a estos cambios. Argumentaremos que se trata de un cambio de época, caracterizado como un proceso de modernización conservadora, rápida y multifacética, cuyas tensiones y limitaciones ayudan a explicar el giro de América Latina hacia la izquierda en la primera década del siglo XXI.

Basándonos en la obra clásica de Barrington Moore (1966), vemos la modernización conservadora como un proceso en el que ciertas esferas de la sociedad cambian con base en relaciones sociales "modernas" (capitalistas, burocráticas y democráticas), mientras que otras permanecen dominadas por cierres sociales elitistas (relaciones sociales basadas en la coerción, política tradicional elitista y jerarquías basadas en el estatus). La idea de modernización asincrónica recupera también las perspectivas de Gino Germani (1962) y Peter Heintz (1964). Moore veía la modernización conservadora como la ruta a la modernidad en países donde las élites permitieron la industrialización, promovieron la educación y la construcción del Estado, a la vez que intentaban mantener el orden y la sociedad estamental mediante acuerdos corporativos y autoritarios que incluían formas de control no basadas en el mercado. Por su parte, Heintz sostuvo que la modernidad en América Latina seguía siendo desigual, que garantizaba el acceso solamente a ciertas dimensiones de la modernidad (posibilidad de vivir en las ciudades, tener cierta escolaridad, ser trabajador industrial), pero no a otras (pertenecer a las clases medias, alcanzar ciertas capacidades de consumo, plena ciudadanía democrática). Esto fue el resultado directo de las intervenciones de las élites económicas y políticas, así como de ciertos sectores de la clase media, que no estaban dispuestos a extender ciertas fuentes de estatus, bienestar y poder al resto de la sociedad. Tanto 
para Moore como para Heintz este tipo de desarrollo podría generar crisis de incorporación y presiones para lograr mayor igualdad. Moore era pesimista. El resultado final sería el fascismo como etapa final de la modernización conservadora. Heintz no era ingenuo. En América Latina, el populismo era una de las soluciones a la crisis de incorporación, pero él vislumbraba otras posibilidades. La crisis de anomia que provocaban las inconsistencias de estatus podría resultar en experimentos populistas, democráticos o revolucionarios.

El proyecto de las élites en América Latina en la década de los ochenta conocido como el "Consenso de Washington", fue, en muchos sentidos, un proyecto de modernización conservadora: aceptó e incluso promovió la democracia electoral y la expansión del mercado y de la educación, pero limitó el rango de las políticas que se consideraban aceptables, de manera que la desigualdad y la distribución inequitativa de oportunidades permanecieron como una característica dominante en la región. Pero insistiremos en esta idea: no son simplemente la desigualdad, la pobreza y la exclusión las bases del desarrollo político reciente. Es resultado de la combinación con transformaciones socioeconómicas (urbanización, incorporación al mercado de trabajo, desarrollo educativo, nuevos patrones de consumo), además de un elemento crítico, de carácter político: la expansión de la democracia electoral durante los últimos 25 años.

Trataremos de demostrar que el "giro a la izquierda" en América Latina es una expresión política de lo que en la sociología política de los años cuarenta y cincuenta fue conocido como crisis de incorporación. Este tipo de crisis ocurren cuando la necesidad de interacción cooperativa en los mercados y en la política, así como la presión desde abajo en términos de demandas económicas, políticas y sociales no están siendo atendidas por los patrones institucionales de incorporación y regulación. El contenido desborda los canales. En el periodo de la posguerra esta idea se aplicó para explicar el surgimiento de líderes y partidos populistas. La aparición de una clase trabajadora moderna, las crecientes demandas la clase media y la necesidad de dar cabida a grandes masas de migrantes rurales en regímenes que permanecieron políticamente elitistas, económicamente limitados y socialmente excluyentes, crearon grandes tensiones políticas y sociales. El giro populista que dominó la política latinoamericana en esos años fue su más clara expresión. De una manera que recuerda esos eventos históricos, en los años noventa se gestó una segunda crisis de incorporación en América Latina. En la primera década del siglo XXI esta segunda crisis dio a luz a sus descendientes políticos, provocando lo que se conoce actualmente como el "giro a la izquierda" en la región. Este es un cambio 
que resultó de dos padres: democracias electorales ininterrumpidas y deficiencias - y logros - de la era del Consenso de Washington. Hoy en día los descendientes políticos de la segunda crisis de inclusión están dando sus primeros e inestables pasos hacia un cambio sustancial en las estrategias de desarrollo.

\section{Las promesas incumplidas de la modernidad}

Sociológicamente, América Latina fue testigo de una transformación mayor durante las últimas dos décadas, que creó escenarios radicalmente diferentes en las fronteras e interacciones entre familias, mercados y Estado. Esta transformación es fundamental para entender las micro-bases de la crisis política de incorporación que describiremos en la siguiente sección. En otras palabras, es crucial para entender cómo se moldean y movilizan las preferencias políticas colectivas en América Latina.

El final del modelo ISI y la confianza en el Consenso de Washington tuvieron un efecto radical al convertir las relaciones de mercado en el canal predominante por medio del cual la gente busca y obtiene un lugar en el mundo. Esta transformación estuvo acompañada de dos factores adicionales: paisajes urbanos transformados y expandidos y la revolución de las comunicaciones, que aumentó la difusión de nuevos patrones de consumo mediante sus efectos demostrativos. En otras palabras, sustancialmente más personas estaban viviendo juntas en ciudades, se estaban convirtiendo en trabajadores potenciales $\mathrm{y}$, de hecho, buscaban abiertamente la participación en el mercado laboral, como se observa en la figura 1.

La entrada de las mujeres al mercado de trabajo transformó profundamente a las familias, las empresas y los mercados, como se muestra en la figura 2.

En los años noventa hubo un incremento tangible tanto en la población en edad de trabajar como en las tasas de participación laboral, pero no se incrementaron las tasas de ocupación. Esto significa que la ocupación aumentó a un ritmo inferior al que requería la evolución de la pirámide de edad y de las tasas de participación.

Como se advierte en la figura 3, a excepción de Panamá y Bolivia, la tasa de ocupación en América Latina no creció. Además, la expansión de la ocupación se llevó a cabo, principalmente, mediante la incorporación de las mujeres por la vía de la economía informal. Solamente cuatro países han sido capaces de disminuir el porcentaje de trabajadores informales en la economía: Chile, Argentina, Brasil y, ligeramente, El Salvador (Tokman, 
Figura 1. Población en edad de trabajar, tasa de participación en el mercado laboral y población urbana en América Latina , 1980-2006

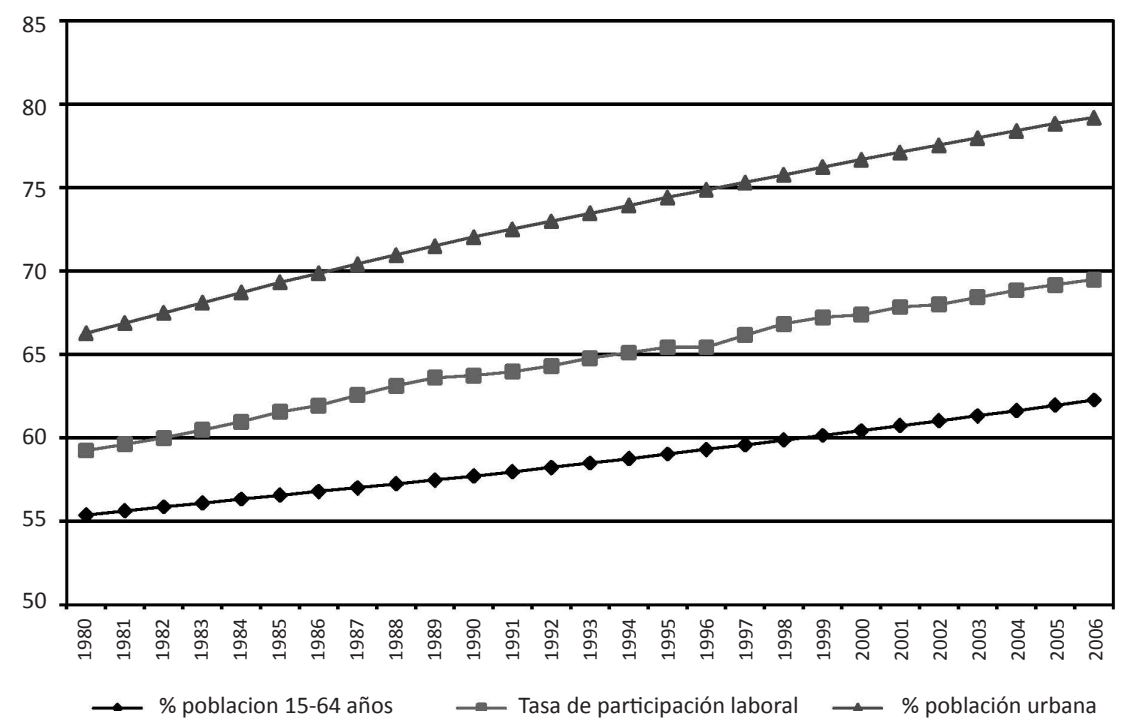

Fuente: World Development Indicators, World Bank, 2009. Promedio no ponderado para 17 países.

Figura 2. Porcentaje de mujeres en edad de trabajar que participan en el mercado laboral en América Latina, 1980-2006

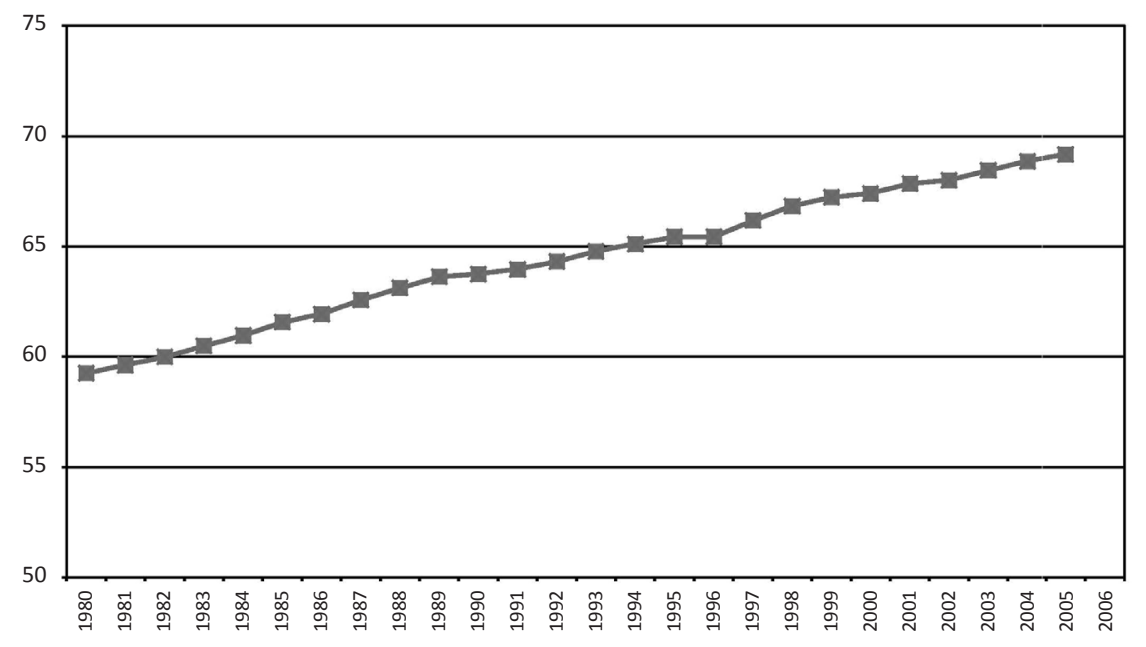

Fuente: World Development Indicators, World Bank, 2009. Promedio no ponderado para 17 países. 
Figura 3. Tasa de ocupación en América Latina en dos periodos: 1989-1999 y 2001-2005

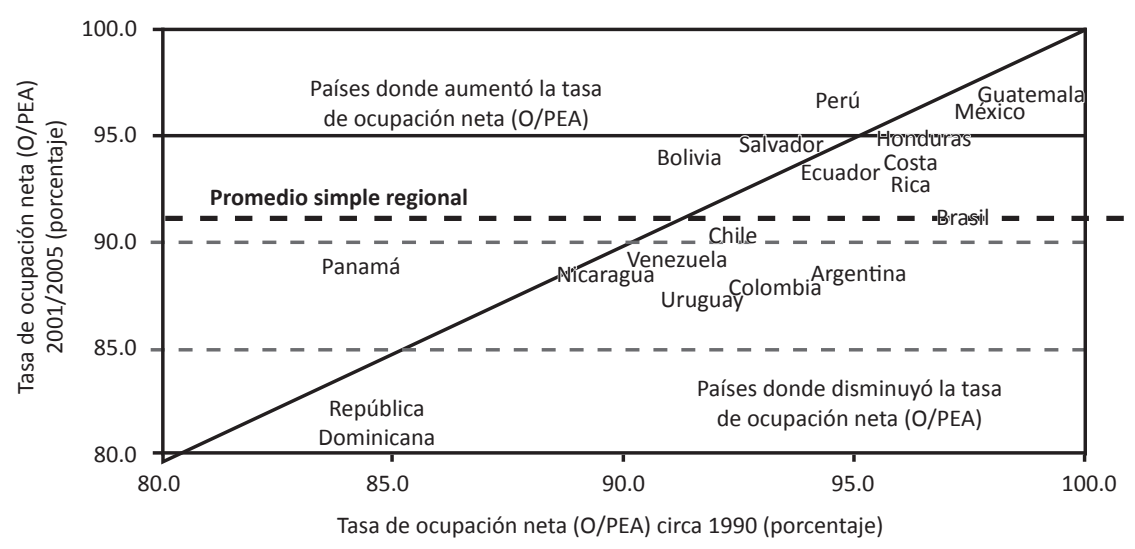

Fuente: Cecchini y Uthoff, 2007.

2007). La promesa de inclusión en la modernidad mediante la inserción en el mercado de trabajo fracasó, no porque no hubiera incorporación, sino porque fue frágil y precaria. Hubo tres factores que generaron dicha precariedad. En primer lugar, en las nuevas incorporaciones predominaron las mujeres, quienes tenían menor experiencia laboral y sindical que los hombres, por lo que se encontraban en una situación más desventajosa para negociar sus condiciones de contratación y de trabajo. En segundo lugar, entraron a un mercado de trabajo transformado: más desigual, con menos garantías y más desempleo. En tercer lugar, la desigualdad y el desmantelamiento de los viejos regímenes de bienestar orientados hacia los trabajadores industriales no trajeron derechos sociales y ciudadanía social. A excepción de Chile y, en menor medida, México y Brasil, los latinoamericanos encontraron que, a pesar de que trabajaban más que antes, obtenían menores ingresos y sus empleos eran más inseguros.

Algunos sectores de las clases medias y las élites tuvieron acceso a niveles y patrones de consumo inimaginables pocos años antes. $Y$ todo el mundo lo veía. Además, muchos de los que no se beneficiaron de estas mejoras consideraban que tenían derecho a ellas. Tenían ya un tiempo de haberse convertido en habitantes urbanos. Habían alcanzado mayores niveles educativos, pero la movilidad intra e intergeneracional parecía haberse detenido.

El cuadro 1 muestra la gran transformación reciente en relación con los nuevos patrones de consumo en América Latina. Durante el periodo 1995- 
2010 el acceso a teléfonos celulares e internet y las computadoras creció más rápido que el $\mathrm{PIB}$, el ingreso nacional o los ingresos de los pobres y las clases medias. Aunque el porcentaje de usuarios de internet en América Latina es menor que el de Europa o América del Norte, es superior al de otras regiones. En lo que se refiere a suscripciones a teléfonos móviles, en 2010 América Latina llegó a 98.2 por cada 100 habitantes, superando incluso a Canadá (70.4) y a los Estados Unidos (90.2).

Cuadro 1. Teléfonos móviles y usuarios de internet por cada 100 habitantes, 1995-2010, regiones y países seleccionados

\begin{tabular}{lrrrrrrrr}
\hline \multicolumn{1}{c}{$\begin{array}{c}\text { Año } \\
\text { Región o país }\end{array}$} & \multicolumn{3}{c}{$\begin{array}{c}\text { Suscripciones de teléfonos móviles por } \\
\text { cada 100 habitantes }\end{array}$} & \multicolumn{5}{c}{$\begin{array}{c}\text { Usuarios de Internet por cada } 100 \\
\text { habitantes }\end{array}$} \\
\cline { 2 - 9 } & 1995 & 2000 & 2005 & 2010 & 1995 & 2000 & 2005 & 2010 \\
\hline $\begin{array}{l}\text { Países menos } \\
\text { desarrollados }\end{array}$ & 0.0 & 0.3 & 4.9 & 33.4 & 0.0 & 0.1 & 1.0 & 4.4 \\
$\begin{array}{l}\text { Países de desarrollo bajo } \\
\text { y medio }\end{array}$ & 0.3 & 4.3 & 24.2 & 72.5 & 0.0 & 0.6 & 7.1 & 21.3 \\
$\begin{array}{l}\text { Mundo árabe } \\
\text { Este de Asia y Pacífico }\end{array}$ & 0.2 & 3.1 & 26.9 & 87.7 & 0.0 & 1.2 & 8.0 & 26.5 \\
América Latina y el Caribe & 1.3 & 11.4 & 34.4 & 76.6 & 0.2 & 5.6 & 14.7 & 35.6 \\
Canadá & 0.8 & 12.3 & 43.3 & 98.2 & 0.1 & 3.9 & 16.6 & 34.0 \\
Estados Unidos & 8.8 & 28.4 & 52.7 & 70.4 & 4.2 & 51.2 & 71.6 & 81.9 \\
Unión Europea & 12.7 & 38.8 & 68.9 & 90.2 & 9.2 & 43.1 & 68.2 & 79.3 \\
\hline
\end{tabular}

Fuente: World Development Indicators, World Bank, 2009.

El problema no es la transformación de hábitos de los consumidores ni la exposición a la urbanización; es la enorme brecha entre las promesas de la modernidad y la capacidad de una gran parte de la población para realmente acceder a lo que muestran los programas televisivos, o a lo que sólo $20 \%$ de las familias obtiene. Cuando la familia y el trabajo cambian hacia una mayor inestabilidad, de múltiples familias y trabajos, el consumo adquiere un papel central en la definición del lugar de cada persona en el mundo. Como argumentó Carlos Filgueira en su artículo seminal sobre patrones de consumo en América Latina (1981), hay dos formas principales mediante las cuales una sociedad puede lidiar con la brecha entre las expectativas legítimas de consumo y el acceso real. Una de ellas es la expansión masiva de la capacidad económica y, por tanto, del consumo - lo que permite a las personas acceder a lo que antes no estaba a su alcance-; la otra es incrementar la fluidez en términos de movilidad social que, si 
bien no provee a todos acceso a nuevos patrones de consumo, estratificará ese acceso a lo largo de líneas meritocráticas legítimas. Si no se produce ninguno de estos dos desarrollos se generan demandas no satisfechas y comienza a predominar una percepción de injusticia.

La percepción de inequidad también tiende a dominar cuando la movilidad educativa es mayor al ingreso y a la movilidad ocupacional. Éste ha sido precisamente el caso en América Latina, quizás a excepción de Chile. Carlos Filgueira (1983) documentó un patrón similar durante los años setenta y principios de los ochenta. El resultado fue un sistema que aumentaba las expectativas sin proporcionar oportunidades. En los años noventa, una de las transformaciones sociales más radicales fue la relacionada con los logros educativos. El énfasis en la formación de capital humano en esa década tuvo efectos en el acceso a la educación y en las tasas de terminación. Para 2005 la tasa de alfabetización en la región llegó a 95.8\%. Entre los niños en edad de cursar la primaria, la tasa neta de asistencia pasó de $90 \%$ en 1990 a 94\% en 2005, mientras que en educación media básica se incrementó de 61\% en 1990 a 76\% en 2005 (CEPAL, 2007: 161). Además de la asistencia, también mejoró el desempeño en esos niveles, ya que entre niños y jóvenes de 10 a 14 años de edad el progreso educativo oportuno pasó de $61 \%$ en 1990 a $80 \%$ en 2005, mientras que entre jóvenes de 15 a 19 años el progreso educativo oportuno aumentó de $48 \%$ en 1990 a 69\% en 2005 (CEPAL, 2007: 164). Las tasas de finalización de la educación primaria se incrementaron significativamente, sobre todo en las áreas rezagadas de la región; también fue impresionante el avance en el porcentaje de graduados en educación media superior, que pasó de $27 \%$ en 1990 a 50\% en 2005, entre jóvenes entre 20 y 24 años de edad (CEPAL, 2007: 167).

Por supuesto, la mejora en las tasas de acceso y eficiencia terminal en la educación no significa que las oportunidades de empleo hayan mejorado, ni que la distribución de la calidad educativa sea mejor. Precisamente, el problema es la reproducción de la desigualdad de la educación en términos de calidad y los efectos tan exiguos que el aumento de la escolaridad tiene sobre los ingresos y la movilidad ocupacional. En los últimos 10 años en que se elevó la eficiencia terminal en la educación básica, disminuyeron las primas educativas que otorga ese nivel y se trasladaron hacia niveles educativos a los que solamente unos pocos tienen acceso. En otras palabras, la educación no logra buenos resultados como instrumento de acompañamiento de la movilidad estructural, y menos aún como medio para moverse meritocráticamente hacia arriba en la dinámica de movilidad de remplazo. 
Un último factor que expone los avances y fracasos de incorporación es el proceso de urbanización de América Latina. Como la palabra ciudad sugiere, es el ámbito donde los desiguales comparten un grado de igualdad, donde las diferencias de ingresos no suponen diferencias de ciudadanía. Pero cuando las ciudades están segregadas, pierden su función de inclusión. Sin embargo, no desaparece la influencia de las ciudades en generalizar expectativas y aspiraciones; lo que se pierde son los canales institucionales y sociales para alcanzarlas. Se difundieron ampliamente patrones de consumo que se han vuelto símbolos de estatus en la modernidad, pero se mantuvo la segregación en lo que se refiere a las normas y los medios para acceder a dicha modernidad.

\section{El impulso por la democracia y su fragilidad}

Al mismo tiempo que América Latina atravesaba por estos cambios socioeconómicos masivos durante los últimos 25 años, también experimentó un cambio político profundo. En 1975 solamente cuatro países (Colombia, Costa Rica, Venezuela y República Dominicana) tenían elecciones democráticas y sólo uno las había tenido por más de 20 años: Costa Rica. En 2000, la mayoría de los países en América Latina tenían democracias electorales, pese a las carencias que pudieran tener en cuestiones de inclusión social o de respeto a las libertades democráticas (Smith, 2004).

Se puede argumentar que varios países después de regresar a la democracia pasaron por periodos semidemocráticos o autoritarios, pero ninguno dejó de tener elecciones periódicas. Mediante un cálculo simple podemos estimar el incremento de la exposición a procesos electorales en América Latina durante los últimos 25 años. La fórmula es simple. Si contamos cada país y su población, y lo clasificamos con base en si tiene o no democracia electoral, se puede establecer una cronología de la proporción de latinoamericanos expuesta a procesos electorales durante los lustros recientes.

La curva es impresionante. Otro dato crucial es que nunca antes tantas democracias se habían mantenido por tanto tiempo en América Latina (Smith, 2004: 10). Sin embargo, la enorme desigualdad en la distribución de los recursos sociales y políticos subvierte el espíritu de igualdad que está en la columna vertebral de los ideales democráticos. Si bien las democracias electorales han perdurado, muchos han dicho que carecen de la sustancia, la calidad, la profundidad y la estabilidad que se esperaría de las democracias "consolidadas". De hecho, aunque los regímenes autoritarios 
Figura 4. La incorporación de las masas a la democracia electoral en América Latina

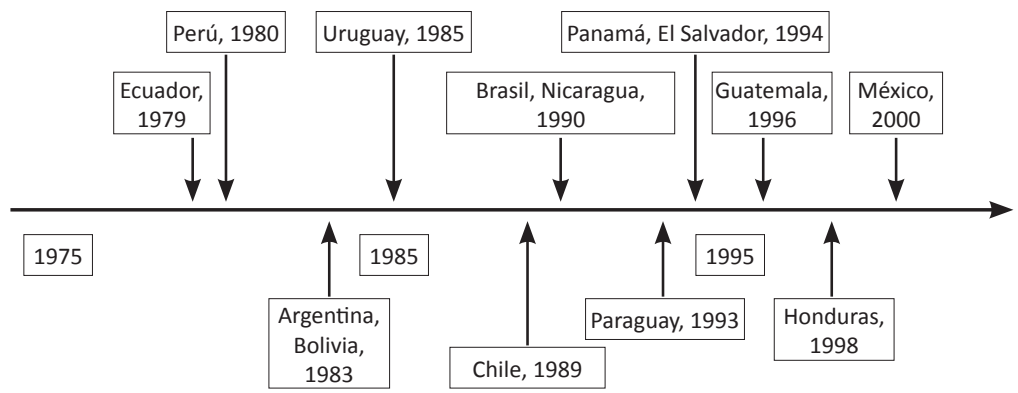

Fuente: Smith, 2004, Przeworski et al., 2000.

Figura 5. Proporción de la población latinoamericana que vive en democracias electorales, 1975-2010

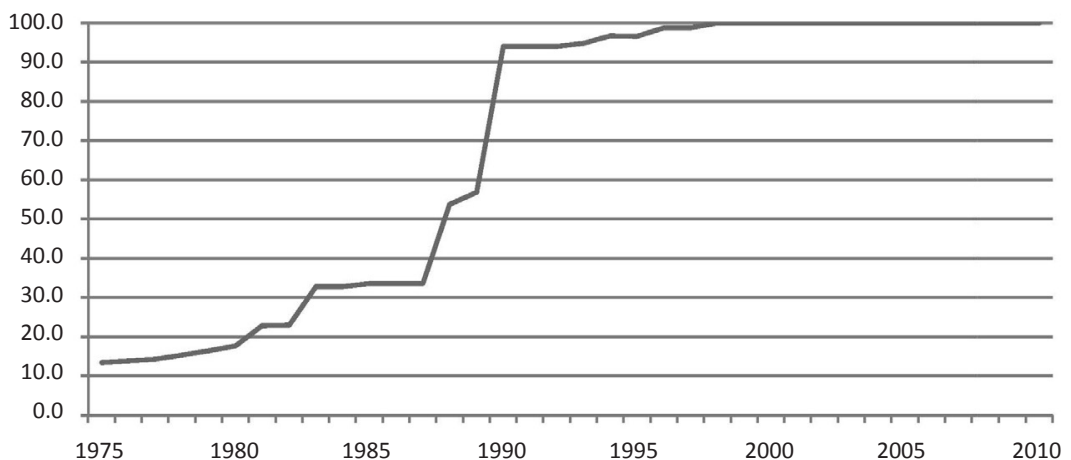

Fuente: Elaboración propia basada en estimaciones de población del Banco Mundial para 2000, y datos de Smith (2004) para la clasificación de los regímenes democráticos.

han disminuido abiertamente desde los años ochenta, es posible observar al menos tres procesos que han erosionado la fe en esta nueva ola de regímenes democráticos:

a) Muchos países de la región enfrentaron crisis políticas de enormes magnitudes; algunos, con dificultad, lograron canalizarlas por la vía democrática, mientras que otros se embarcaron en los riesgosos caminos de las democracias plebiscitarias y los autoritarismos "constitucionales". 
b) En un número importante de países se ha observado que crecieron la apatía ciudadana, el desinterés y la desconfianza en los mecanismos democráticos. En muchos casos este clima de opinión se ha acompañado de episodios de protestas anómicas y violentas, carentes de propósitos políticos estructurados.

c) La paradoja de la democracia en la segunda mitad del siglo XX es que, mientras antes de los años ochenta significaba inclusión política genuina (acceso al poder, especialmente para los sectores populares) y lucha por la redistribución, la democracia era profundamente inestable; después de los años ochenta, en medio de una deflación ideológica y una creciente aceptación de los límites impuestos por el Consenso de Washington, la democracia ha resultado ser, sin duda, más estable, pero menos significativa en términos de su potencial para resolver la crisis de incorporación.

Las sociedades latinoamericanas presentan niveles de desigualdad y pobreza que casi dos décadas de democracia no han podido resolver: en muchos casos, la pobreza se ha mantenido en niveles asombrosamente altos $\mathrm{y}$, en casi todos, las desigualdades se han hecho más profundas. Esto marca un doble reto al futuro democrático en la región: el desafío de fortalecer o incluso construir los pilares sociales de la democracia y el de demostrar a la ciudadanía que la democracia puede tener un impacto positivo sobre el bienestar social. Como se muestra en la figura 6, esa "función social de la democracia" no se ha conseguido porque, pese a la generalización de la democracia electoral en la región, no ha disminuido la proporción de latinoamericanos que vive en condiciones de pobreza.

Los antiguos sistemas de partidos fueron puestos bajo la mira por nuevos contendientes sociopolíticos. Estos partidos tuvieron que representar el desagradable papel de ser los enterradores del modelo ISI y dedicarse a la compleja construcción del nuevo modelo centrado en la apertura de los mercados. En la región más desigual del mundo, con democracias electorales cada vez más competitivas y con una retórica y un modelo que miraban con abierta animosidad al Estado, los viejos partidos intentaron lo imposible: mantener la legitimidad en un contexto democrático, al mismo tiempo que renunciaban al Estado. El resultado final no fue sorprendente. El Consenso de Washington se contaminó de políticas patrimonialistas que impidieron construir coaliciones estables. El paisaje político se pobló cada vez más de cadáveres políticos que daban paso, primero, a líderes semiautoritarios y tecnócratas con mentalidad de mercado, y después a nuevos partidos o viejos contendientes que apelaban a una base social más o me- 
Figura 6. Proporción de la población de América Latina que vive en democracias electorales y proporción que vive debajo de la línea de pobreza, 1975-2005

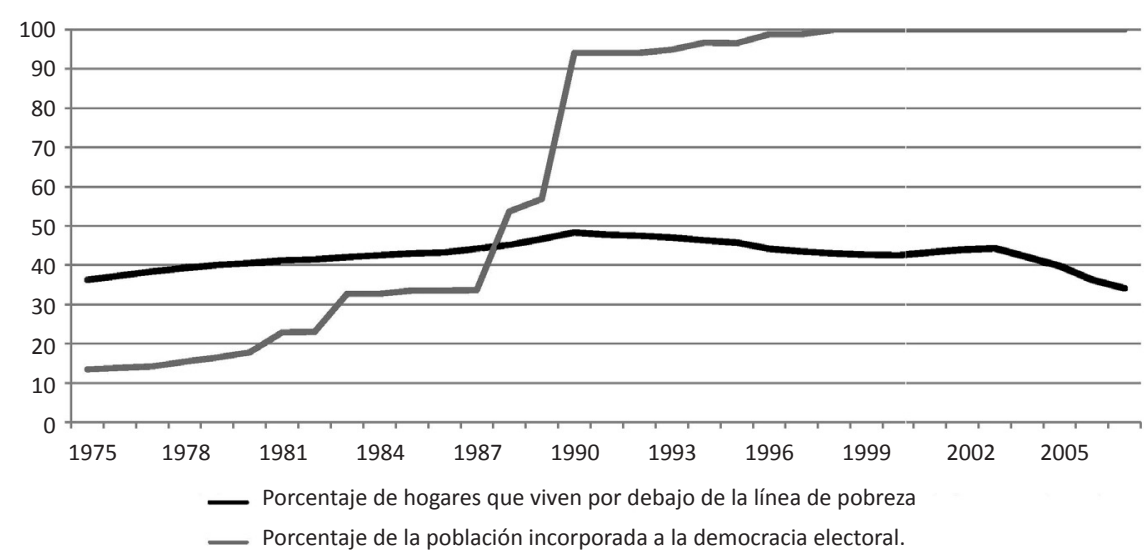

Fuente: World Development Indicators, World Bank, 2009; Smith, 2004 y estimaciones de pobreza basadas en ECLAC, 2006.

nos heterogénea, que incluía las clases medias, históricamente excluidas y cada vez más nerviosas. Menem, Collor de Melo, Salinas de Gortari y Fujimori son parte de la misma crisis de incorporación que hoy fortalece a las opciones de izquierda.

La crisis de incorporación que estamos presenciando actualmente es resultado, al menos en parte, del descuido de la capacidad del Estado como instrumento fundamental para conseguir la inclusión en América Latina. No es posible erradicar desigualdades profundas mediante Estados superficiales. La debilidad de las instituciones estatales y la alternancia cíclica entre proyectos de incorporación que, o bien descuidaban el Estado (18701930, 1980-2000) o bien expandieron masivamente la intervención estatal en la economía y la sociedad en el contexto de condiciones internacionales favorables (1930-1980, primera década del siglo XXI), se encuentran en el corazón del movimiento de péndulo de los modelos de desarrollo de América Latina (Roberts, 2008).

\section{El giro a la izquierda como expresión de la crisis de incorporación}

Las políticas derivadas del Consenso de Washington fueron un intento de inclusión complejo y, en última instancia, fallido. Los impulsores de las reformas de mercado entendieron mal la naturaleza del descontento de 
los latinoamericanos y del surgimiento de nuevos reclamos políticos en la región. El neoliberalismo no sólo falló por su incapacidad para lograr crecimiento sostenido, distribución de la riqueza e incorporación a los mercados, sino también porque fue incapaz de estructurar la inclusión política, por ejemplo, aplicando políticas capaces de sincronizar las expectativas colectivas y las necesidades individuales. La expansión de las instituciones de mercado y la extensión de derechos políticos entrañaba la promesa de una nueva inclusión, misma que no se logró por medio de la modernización conservadora. El giro hacia opciones de izquierda simboliza el fracaso de ese intento de incorporación, basado en la inclusión electoral en democracias frágiles y en la incorporación a un mercado segmentado. Como sugeriría una lectura contemporánea del trabajo clásico de Karl Polanyi, estos regímenes políticos y sociales se mostraron incapaces de proveer los cimientos institucionales que los mercados necesitan para garantizar crecimiento sostenido y equitativo (Kurtz, 2004; Roberts, 2008).

El giro a la izquierda puede ser visto como un intento de enfrentar la crisis de incorporación generada por la combinación entre desigualdades persistentes, Estados superficiales, apertura económica, modernización conservadora y democracia electoral. Por supuesto que no es la única respuesta posible frente a esas crisis; existen otras alternativas y de hecho se han puesto en práctica otras vías, por ejemplo las que pusieron en práctica Vicente Fox y Felipe Calderón en México, Álvaro Uribe en Colombia y Álvaro Colom en Guatemala, que combinaron importantes programas de transferencias monetarias condicionadas a los pobres con alianzas fuertes con sectores empresariales y una especie de populismo de derecha.

El surgimiento de cambios políticos drásticos puede verse como el deseo de cambio en la gente y como evidencia de conflicto. Pero desde nuestro punto de vista, un cambio político radical es más sistémico y los factores que lo impulsan son más profundos. Los cambios radicales en las élites de gobierno, aunque no sean violentos, tienden a ser producto de crisis sistémicas y no de cambios de opinión coyunturales.

En varios países de América Latina durante la primera década del siglo llegaron al poder dirigentes que se distanciaron del Consenso de Washington y que se ubican hacia la izquierda en el espectro político. Sin embargo, el cambio a la izquierda no puede atribuirse a un realineamiento del conjunto de la población en términos ideológicos. La información simplemente no respalda esto, si por posición ideológica asumimos la ubicación autodeclarada en el continuum izquierda-derecha. Pero existen indicios de que hay un cambio de actitud, que se relaciona con la reducción de la tolerancia a la desigualdad. Como Blofield y Luna documentan 
(2008), entre 1990 y 2000, en casi todos los países considerados creció el porcentaje de personas que afirmaron que sus sociedades deberían ser menos desiguales. También ha cambiado lo que en América Latina se consideran "políticas adecuadas" y "preocupaciones centrales". Como señala acertadamente Arditi:

The current standard of what constitutes the center is more clearly a creation of the left. It includes strengthening the state to regulate markets, and curb excesses of privatization [...] increasing social expenditures [...] politicizing questions of cultural and ethnic exclusion and experimenting with new participatory channels [...] (Arditi, 2008: 71).

Observando las victorias electorales de líderes de izquierda en la primera década del siglo XXI, es posible afirmar que comparten similitudes con respuestas históricas a situaciones de crisis de incorporación y a etapas iniciales de intentos de incorporación: apoyo de una base social heterogénea, retórica en contra de las élites tradicionales y de los grupos en el poder, movilización significativa por un líder carismático y evento disparador (por ejemplo, la crisis económica). No hay un cambio ideológico drástico, sino más bien un cambio de actitud que intuitivamente se dirige hacia la raíz del descontento (la desigualdad). El cambio serio y durable en la ideología sucede cuando la crisis no sólo se ha expresado políticamente, sino cuando esa expresión es capaz de construir una coalición institucionalmente estable que sostenga políticas a largo plazo que garanticen las reformas de las bases - o de algunas de ellas - que crearon la crisis de incorporación.

A principios del nuevo milenio, el giro hacia la izquierda se ha producido en cada país con marcadas diferencias en las formas de participación, representación e incorporación. Hay posiciones muy distintas frente a la democracia representativa y se han generado políticas con contenidos muy diversos, por lo que es más conveniente hablar de "izquierdas", en plural, y no de una sola izquierda. Hay una lógica estructural que explica la divergencia en los modelos de izquierda en la región. La trayectoria de cada país depende conjuntamente de los tipos específicos de integración a la economía internacional, de los dispositivos de protección y regulación frente a esta integración, así como de los formatos de representación e inclusión política que afectan el sistema de partidos.

El surgimiento de gobiernos de izquierda ha provocado una verdadera explosión de textos desde la academia (Cleary, 2006; Panizza, 2005, Roberts, 2007; Castañeda 2006, Weyland, 2009; Schamis, 2006; Lanzaro, 2006; Luna, 2007; Corrales, 2006). Sin embargo, estos acercamientos difieren significa- 
tivamente en perspectivas analíticas, lo que afecta la manera en que estos gobiernos son clasificados.

En primer lugar, muchos diferencian los gobiernos de izquierda con base en distintos modelos de liderazgo presidencial. Por un lado, en países como Bolivia, Ecuador y Venezuela han surgido líderes considerados por estos autores como "populistas" (Castañeda, 2006), que apuestan por posiciones radicales en el nivel internacional (principalmente en contra de los Estados Unidos de América) y abogan por políticas nacionalistas y por la fuerte intervención del Estado, confrontando directamente a las élites. Por otro lado, hay líderes en Brasil, Chile y Uruguay, considerados "socialdemócratas", que tienen relaciones más conciliadoras con los Estados Unidos, buscan desarrollar políticas amables con el mercado y muestran respeto al sector privado (Castañeda: 2006). ${ }^{1}$

En segundo lugar, para otros autores, la distinción de dos tipos de izquierda está relacionada con el contexto institucional en el que están incrustadas las fuerzas políticas (Weyland, 2009; Panizza, 2005; Schamis, 2006). Mientras que los líderes "populistas radicales" han surgido en países con sistemas de partidos fragmentados o virtualmente disueltos (Ecuador, Bolivia, Venezuela), los líderes de perfil "socialdemócrata" son más comunes en países con sistemas partidistas institucionalizados (Chile, Uruguay) o que han mejorado sus niveles de institucionalización en años recientes (Brasil) (Roberts, 2007; Weyland, 2009; Schamis, 2006; Panizza, 2005). En estos países el sistema partidista fue capaz de canalizar el descontento con las políticas pro mercado mediante ofertas políticas integradas en la contienda electoral, sin tener que recurrir a un rediseño constitucional como el que se produjo en Bolivia, Ecuador y Venezuela. ${ }^{2}$ En esos casos, los partidos de izquierda pasaron por

1 En este artículo no analizamos el caso de México, ya que en este país la izquierda no ha llegado a la Presidencia de la República. Pero México también tuvo su "giro a la izquierda", expresado sobre todo en la conquista del gobierno de la ciudad de México por el Partido de la Revolución Democrática en 1997 (ciudad que continúa hasta la fecha gobernada por la izquierda), y por el ascenso de Andrés Manuel López Obrador, quien perdió la elección presidencial por escaso margen en los controvertidos comicios de 2006. En lo que se refiere a las tipologías sobre las izquierdas en América Latina, los gobiernos del PRD en la ciudad de México podrían considerarse como un caso intermedio que combina rasgos socialdemócratas y populistas, con un fuerte componente corporativo y clientelar.

2 A este respecto, Argentina constituye un caso intermedio, porque experimentó una profunda crisis económica y política en 2001 y 2002, cuando en unos cuantos meses cayeron varios presidentes de la república, pero posteriormente salió de esa crisis mediante gobiernos emanados de una corriente política de larga data como es el peronismo. Este carácter intermedio dificulta encasillar a los gobiernos de Néstor Kirchner y Cristina Fernández de Kirchner, que en sentido estricto no corresponden ni a un modelo socialdemócrata ni a uno populista radical. 
procesos de moderación programática, estimulados por la lógica centrípeta generada por los sistemas electorales (Pannizza, 2005).

Finalmente, hay un tercer acercamiento que refleja la tradición de la economía política, que expande las variables explicativas tratando de analizar los tipos de economías exportadoras (Weyland, 2009), la lógica de la representación política partidista y el papel de los movimientos sociales organizados (Roberts, 2007; Luna, 2007). Este último sostiene que la clasificación dominante de gobiernos "populistas radicales/socialdemócratas" no toma en cuenta variables socioestructurales que, vinculadas con las características institucionales, generan secuencias de largo plazo.

En esta última línea de análisis, países con opciones consideradas "populistas radicales" habían experimentado antes crisis de incorporación más profundas. Durante el periodo del modelo ISI, el crecimiento económico estuvo muy ligado a productos de enclave que garantizaron cierta estabilidad en los ingresos fiscales, pero estuvieron acompañados de un proceso de industrialización claramente más lento, menos intenso y más asimétrico en comparación con el de otros países de la región. El sistema de protección social implementado en esos países tenía, comparativamente, menor cobertura, con un porcentaje significativo de sectores rurales y urbanos no protegidos. En términos políticos, el proceso de expansión y extensión de la participación política fue irregular: o bien los partidos y movimientos que integraban los sectores populares fueron sometidos (Ecuador), o las coaliciones radicales que trataron de ampliar la participación política fueron contrarrestadas por los ciclos de represión y restricción política (Bolivia), o neutralizadas por pactos en las élites que aseguraban estabilidad institucional con el costo de minimizar la apertura en el sistema partidista (Venezuela).

Durante la fase del Consenso de Washington, estos países reestructuraron sus economías extendiendo la apertura de sus principales mercados de exportación, ${ }^{3}$ y desmantelaron los limitados dispositivos de protección social construidos en la etapa anterior. El estallido de los modelos de mercado ocurrió en un contexto de activación de movimientos populares o étnicos que no habían sido incluidos en la era del modelo ISI. Como resultado, los procesos de recomposición de algunos de los movimientos o partidos

3 Estos países no fueron los únicos que en los últimos lustros priorizaron su relación con el mercado mundial a partir de la exportación de materias primas; esta característica se encuentra presente en muchas de las economías de América Latina. Sólo queremos destacar que en algunos casos esa tendencia se había presentado durante el periodo previo y había tenido efectos negativos sobre la estabilidad institucional. 
(MNR en Bolivia, AD en Venezuela) terminaron en crisis y en su eventual desaparición, arrastrando con ellos todo el sistema partidista. En Ecuador el proceso de surgimiento de nuevos movimientos en la arena política desafió el sistema partidista tradicional y elitista.

Un segundo grupo de casos son Chile, Brasil y Uruguay, cuya primera crisis de incorporación fue mejor procesada. El hecho que hayan seguido una "ruta socialdemócrata" no puede explicarse solamente por las características personales de los presidentes o por los niveles de institucionalización de los sistemas de partidos. También tiene que ver con la expansión previa del modelo ISI anclado en el desarrollo de áreas urbanas y en el crecimiento de la industrialización. Adicionalmente, a diferencia de los países andinos, fueron capaces de desarrollar sistemas de protección social con mayor cobertura y extensión, a pesar de su dualismo y estratificación (Filgueira, 1999). Generalmente estos dispositivos iban acompañados por el desarrollo de procesos de inclusión y movilidad social, que surgieron ya fuese de manera vertical y canalizada por medio de movimientos populistas o por partidos radicales (en los casos de Brasil y Chile) o por partidos clientelistas que integraban los segmentos medios y bajos (Uruguay).

En los tres casos, el proceso de reformas de mercado y la transformación de los patrones de representación política y de incorporación social ocurrieron en contextos de estabilidad institucional y mayor presencia del Estado. Los partidos de izquierda articularon de diferentes maneras sus enlaces con sus bases sociales, en algunos casos capitalizando los activos heredados de la era del modelo ISI (PT - Partido dos Trabalhadores - en Brasil, FA - Frente Amplio - en Uruguay). También ajustaron sus programas y estructuras a una competencia electoral más moderada. Los partidos existentes en estos países pudieron regular mejor las demandas de inclusión social.

Cabe señalar que no debe exagerarse el poder explicativo de cualquier tipología dicotómica que intente encasillar las diversas experiencias de varios gobiernos de izquierda en una simple oposición entre "populistas radicales" y "socialdemócratas" (o cualquier otra tipología similar), ya que existen diversos clivajes que crean similitudes y diferencias entre los países. ${ }^{4}$ Además, cada país tiene una trayectoria particular y se pueden encontrar algunas similitudes entre las políticas públicas de países que usualmente son ubicados en "tipos" diferentes, por ejemplo las que existen entre Chile

4 Por ejemplo el clivaje regional que distingue a los países de América Central de los de América del Sur, y en este último caso entre los países andinos y los países del Cono Sur. 
y Colombia o entre Brasil y Argentina. También existen contrastes muy marcados dentro de cada uno de los tipos más usuales. ${ }^{5}$

En cualquier caso, los gobiernos de izquierda han comenzado a enfrentar el legado de la desigualdad y el fracaso de la promesa de la inclusión basada en el mercado. Para ello recurren a diferentes herramientas que despliegan un nuevo menú de opciones de políticas, pero es un menú que no es perfectamente consistente ni evidentemente estable. Ahora analizaremos estas diferentes opciones, enfocándonos en las políticas que están estrechamente relacionadas con el bienestar y los problemas de distribución.

\section{Opciones de política social, tentativas de incorporación}

Las herramientas liberales en manos de la izquierda: transferencias condicionadas

Los gobiernos de izquierda han reasumido, extendido o lanzado programas de transferencias monetarias dirigidos a los pobres, que eran herramientas previamente aceptadas en el repertorio de políticas sociales en la región. Estos programas incrementaron el monto de las transferencias, otorgaron mayores beneficios o extendieron la cobertura. En Brasil, el gobierno de Lula impulsó los programas Hambre Cero y Bolsa Familia, que en 2005 cubrieron a más de siete millones de familias. En Chile, el programa Chile Solidario combinó transferencias en efectivo con componentes promocionales, apoyo psicosocial y atención personalizada, con una cobertura de 250000 familias (Serrano, 2005: 51-52). En Ecuador el gobierno de Rafael Correa duplicó el monto del Bono de Desarrollo Humano de 15 a 30 dólares al mes, aumentó la cobertura para incluir a los discapacitados, y dobló el Bono de Vivienda de 1800 a 3600 dólares (Ramírez y Minteguiaga, 2007: 98).

Una variante de las transferencias condicionadas son los programas de ayuda monetaria para los desempleados. En Argentina, después de la crisis de 2001, el gobierno desarrolló el Plan Jefas y Jefes de Hogar Desocupados, y en 2003 este programa cubría casi a dos millones de personas, superando por mucho a programas previos de la misma naturaleza (Golbert, 2004: 2325). El plan nació en un contexto de gran movilización social y, a diferencia de los programas de transferencias monetarias que usan un lenguaje

5 Baste mencionar los enormes contrastes entre los procesos políticos de tres países que suelen ser colocados en el mismo grupo en la mayoría de las tipologías: Venezuela, Bolivia y Ecuador. 
paternalista o de formación de capital humano, se basó en un discurso de justicia social.

En Uruguay, el presidente Tabaré Vázquez estableció en 2005 el programa PANES (Plan de Atención Nacional a la Emergencia Social) para atender situaciones de exclusión. Además del Programa de Ingreso Ciudadano (transferencias mensuales de 56 dólares), PANES incluyó otros aspectos, entre ellos empleo temporal (Trabajo para Uruguay), nutrición, salud y educación en contextos críticos y vivienda para quienes no la tenían (Svlestuen, 2007). Además, el PANES adoptó el discurso del derecho a inclusión y fue un programa temporal, que fue sustituido por el Plan de Equidad en 2007.

¿Por qué algunos gobiernos de izquierda han utilizado estrategias liberales y han continuado programas de alivio a la pobreza en lugar de combatir la desigualdad mediante programas universales más en sintonía con sus ideologías? Es probable que esto se deba a varios factores: 1) inercia institucional, dado que encontraron estos mecanismos en marcha y podrían continuarlos y ampliarlos con relativa facilidad, sin tener que hacer ninguna reforma estructural; 2) recursos limitados: los programas focalizados son menos costosos que los universales; 3 ) conveniencia política: conceden gran legitimidad a un bajo costo, y 4) oposición limitada, ya que esos programas especializados son bien vistos por fuerzas de centro y de derecha. Sin embargo, parecen ser limitados para resolver la profunda crisis de incorporación que están experimentando los países latinoamericanos.

Las herramientas socialdemócratas: políticas sociales universalistas

El surgimiento de políticas socialdemócratas en América Latina es un fenómeno relativamente nuevo (Lanzaro, 2007). Históricamente, otras izquierdas - nacionalistas, populistas, socialistas - tuvieron mayor relevancia en la región. Gobiernos como los de Tabaré Vázquez, José Mújica, Ricardo Lagos, Michelle Bachelet, Lula da Silva o Dilma Rousseff presentan varias diferencias con respecto a las socialdemocracias europeas, puesto que no se basan en la misma alianza de clases ni en las mismas instituciones del Estado. Sin embargo, el crecimiento de la clase media durante la segunda mitad del siglo $\mathrm{XX}$, los reajustes ideológicos luego de la caída del muro de Berlín, la globalización y sobre todo la consolidación de sistemas partidistas y la participación electoral de la izquierda, crearon condiciones favorables para fortalecer tendencias de izquierda más comprometidas con la democracia representativa y los sistemas de mercado. En sentido estricto, ningún gobierno actual de América Latina puede caracterizarse como so- 
cialdemócrata, pero varios de ellos han utilizado algunas herramientas de política social similares a las que propugna dicha corriente.

En relación con la crisis de incorporación, la estrategia socialdemócrata se caracterizaría por la construcción gradual de la ciudadanía por medio de la regulación (moderada) de los mercados, el fortalecimiento de las instituciones del Estado de bienestar y el énfasis en la nivelación de las capacidades. Bajo esta estrategia, en años recientes han ocupado un lugar importante los intentos por establecer políticas sociales universales. Una de las demandas históricas de la izquierda es garantizar el ejercicio de los derechos económicos, sociales y culturales, para crear así un marco de ciudadanía e igualdad que asegure el acceso universal a la satisfacción de las necesidades básicas. Generalmente, los gobiernos de izquierda usan el discurso de los derechos universales, pero están lejos de lograrlo.

El Plan de Equidad lanzado en septiembre de 2007 por el gobierno uruguayo, parece ser la política más articulada en materia de derechos sociales universales. Sustituyó al PANES y busca reconstruir y modernizar el Estado social. Son notables las propuestas de reformas en los sistemas de salud y educación, que junto con las reformas fiscales y la cobertura extendida de pensiones buscan crear una red de servicios básicos y protección social para todos los ciudadanos, disponible desde la infancia hasta la muerte. El Plan de Equidad incluye medidas que pueden llegar a tener un impacto considerable en la reducción de desigualdades, entre las que destaca un sistema de asistencia social no contributivo que abarcaría a 95\% de las familias que viven bajo la línea de pobreza, la expansión sustancial de la educación previa a la escuela primaria, la ampliación de los beneficios de jubilación y acciones para mejorar la calidad de la educación en todos los niveles. El diseño del plan apunta a una estrategia socialdemócrata de universalismo básico y extensión gradual de asistencia social no contributiva (Andrenacci y Repetto, 2006; Filgueira et al., 2005). ${ }^{6}$

En Chile hubo, hasta antes del gobierno de Piñera, un deslizamiento, si bien lento y zigzagueante, desde posiciones liberales hacia algunos componentes socialdemócratas. Desde el periodo de Lagos (2000-2006), el discurso de los derechos fue efectivamente incorporado al diseño de los programas sociales. En el área de salud, el sistema AUGE (Acceso Universal con Garantías Explícitas) se estableció para determinar enfermedades y patolo-

6 Si bien el Plan de Equidad puesto en marcha en Uruguay constituye un considerable avance hacia políticas sociales universalistas, no debe perderse de vista que, al igual que su antecedente, el PANES, contiene un gran número de acciones focalizadas hacia los sectores más vulnerables. 
gías que deberían ser tratadas universalmente, con derechos exigibles ante los tribunales (Serrano, 2005: 38; Waissbluth, 2006: 42-46). Posteriormente, el gobierno de Bachelet (2006-2010), instituyó el programa Chile Crece Contigo, un sistema de protección infantil que cubre desde el embarazo hasta los cuatro años. El sistema es universal dentro de su ámbito de aplicación y proporciona servicios al $40 \%$ más vulnerable de la población. La tesis es que, si se logra mayor igualdad en esa etapa crucial de la vida, se puede aspirar a mayor igualdad de capacidades para el desarrollo futuro en el sistema educativo y en el mercado de trabajo. ${ }^{7}$

El gran desafío de una estrategia socialdemócrata para crear canales de inclusión a largo plazo es la transición a sistemas universales de educación, salud y seguridad social que trasciendan la atención residual y asistencial de las transferencias monetarias condicionadas. También deben superar el carácter fragmentado, estratificado y corporativo de los viejos sistemas de educación, salud y seguridad social. Hasta ahora, ninguno de los gobiernos de izquierda en América Latina ha logrado avanzar sustancialmente en ese ámbito. Se han enfrentado con la oposición de los sindicatos y con la resistencia de la clase media y alta a las reformas en los sistemas de seguridad social

A pesar de las innovaciones que introducen los enfoques socialdemócratas en las políticas sociales, a los ojos de muchos latinoamericanos no difieren radicalmente de las políticas liberales, porque consideran que hacen muchas concesiones a los sectores privilegiados y llevan a cabo sus programas sociales con demasiada lentitud. Por eso ven con simpatía otras opciones, más radicales.

Las herramientas populistas radicales: campañas sociales e impuestos a la exportación

En países como Argentina, ${ }^{8}$ Bolivia, Ecuador, Nicaragua y Venezuela durante la primera década del siglo XXI se observó una presencia creciente del Estado en el control de la economía y un énfasis renovado de la redis-

$7 \quad$ El hecho de que los gobiernos de Lagos y Bachelet en Chile hayan puesto en práctica algunas políticas sociales universalistas no debe hacer olvidar que durante varios lustros ese país fue el paraíso de las políticas sociales focalizadas.

8 Argentina difícilmente puede ser calificado como "populista-radical". Lo incluimos en este apartado sobre políticas sociales junto a Bolivia, Ecuador, Nicaragua y Venezuela sólo por lo que se refiere a los impuestos a la exportación. El Plan Jefas y Jefes de Hogar Desocupados es más similar a los programas de transferencias monetarias condicionadas que ubicamos entre 
tribución de los ingresos. Una característica distintiva de algunos de los recientes gobiernos de izquierda es su postura radical en cuanto a la captura y distribución de la riqueza, en particular en los años en que los ingresos aumentaron de manera extraordinaria debido a los altos precios de los productos primarios (petróleo, gas natural, metales y productos agrícolas). Para estos gobiernos, el mejor mecanismo para conseguir la equidad es la intervención del Estado en la distribución de la riqueza, para compensar las desigualdades creadas por los mercados. Bajo esta estrategia, destacan medidas como las campañas sociales, los impuestos a la exportación, los subsidios y el control de precios y salarios.

Algunos gobiernos en América Latina han organizado campañas intensivas para combatir la pobreza y exclusión de las poblaciones marginales, urbanas y rurales. El caso paradigmático es Venezuela. El gobierno de Hugo Chávez, beneficiándose de los altos precios del petróleo, ha canalizado recursos sustanciales a campañas cívico-militares llamadas "misiones", que atienden problemas educativos, de salud, alimentarios, etcétera (Lander, 2007: 54-57). Similares a las transferencias en efectivo, las campañas sociales buscan legitimidad política e inclusión, pero lo hacen por medio de diferentes mecanismos. No tienen un carácter residual o específico; más bien están definidas como programas estratégicos dotados de abundantes recursos que permiten una mayor cobertura y una gama de beneficios más amplia, incluyendo componentes no monetarios. Además, las misiones han fomentado instancias de organización popular, en particular la formación de 20000 Consejos Comunales. Las misiones sociales están acompañadas por un discurso radical y no están basadas en las viejas instituciones gubernamentales. Se está creando una nueva institucionalidad, bajo el presidencialismo y con matices corporativistas y clientelistas. Bolivia, Ecuador y Nicaragua han iniciado campañas sociales similares a las de Venezuela, con asistencia de los gobiernos cubano y venezolano, pero con menos recursos y un alcance más limitado (Orellana, 2006; Stefanoni, 2006, y Robinson, 2008).

Bajo el marco neoliberal, las actividades exportadoras gozan de numerosos beneficios fiscales: exenciones, impuestos muy bajos y diversos subsidios. Esto dificultó el desarrollo local, favoreciendo al mismo tiempo el capital internacional. Alejándose de este patrón, varios gobiernos de izquierda empezaron a poner más impuestos a las exportaciones estratégicas. Por ejemplo, en Bolivia, el gobierno de Evo Morales transformó la estructu-

las herramientas liberales, pero en el caso de Argentina tiene un importante componente clientelista combinado con un discurso de reivindicación del derecho al empleo. 
ra fiscal de los hidrocarburos: antes las empresas se quedaban con $82 \%$ de los dividendos y el Estado recaudaba solamente 18\%, proporciones que se invirtieron a partir de 2006. Las ganancias por este enorme aumento en el impuesto se invierten en el proyecto de "capitalismo andino-amazónico", que busca transferir los excedentes de la producción y exportación de hidrocarburos a la economía familiar y comunal (Stefanoni, 2006). En Ecuador, Rafael Correa, desde que era Ministro de Finanzas presionó para reorientar los ingresos por exportación de petróleo hacia el gasto social. Esta política continuó durante su mandato, y aumentó los gastos sociales $15 \%$ en su primer año como presidente (Ramírez y Minteguiaga, 2007).

Si bien la estrategia de altos impuestos a la exportación contribuyó al aumento en la popularidad de los gobiernos que la impulsaron, también ha tenido gran resistencia por parte de las clases medias, las élites locales y las empresas trasnacionales. En Bolivia, este tipo de conflictos se sobreponen con las demandas de autonomías provinciales, dada la concentración territorial de las reservas de gas. En Argentina, en 2008 el gobierno de Cristina Fernández de Kirchner sufrió un duro revés por la oposición que hubo a la modificación del sistema de retenciones a las exportaciones agrícolas (Reygadas y Filgueira, 2010). En Venezuela y Ecuador también ha habido protestas contra los impuestos a la exportación.

Algunos gobiernos de izquierda están tratando de promover la inclusión a través de subsidios y del control de precios y salarios. Esta política se ha aplicado ampliamente en Venezuela y, en menor medida, en Bolivia, Ecuador y Argentina.

La estrategia populista radical ha sido la respuesta más ambiciosa a la crisis de incorporación creada por los fracasos del neoliberalismo en América Latina. Comparado con la estrategia socialdemócrata, el populismo radical opera más rápidamente y más agresivamente para hacer frente a los sectores hegemónicos, reducir los privilegios y entregar más recursos a los grupos excluidos. Sin embargo, es una estrategia con enormes riesgos y costos: se ha concentrado el poder en el ejecutivo, provoca intensas confrontaciones políticas y hay dudas sobre su solidez institucional y sobre su viabilidad política y económica en el mediano plazo, más allá del boom de los precios de los productos primarios.

Independientemente de los alcances y limitaciones de los tres tipos de políticas sociales aquí mencionados, debe señalarse que en la primera década del nuevo siglo hubo otro importante factor de inclusión: la creación de puestos de trabajo, impulsada tanto por el contexto internacional favorable a diversas exportaciones latinoamericanas como por cambios en las políticas macroeconómicas de algunos gobiernos aquí analizados. 


\section{Final abierto}

América Latina se ha desplazado hacia la izquierda, no hay duda al respecto. Lo que está por verse es si se trata de una transformación estructural o un cambio más bien coyuntural. Lo que no es coyuntural es el fundamento de este cambio político: el colapso de la tentativa democrático-liberal por impulsar la inclusión con base en el mercado, que dominó desde los años ochenta hasta el final del siglo. Los fracasos y éxitos de la crisis de incorporación son realidades y demandas políticas que llegaron para quedarse. Si la solución a esta crisis de incorporación tendrá a la izquierda a la cabeza, es otro tema, para el que no tenemos respuesta. Pero quien sea que esté al frente de los nuevos intentos de inclusión en un futuro próximo, tendrá que resolver las contradicciones inherentes creadas por la democratización de las expectativas y de los procedimientos políticos, en un contexto social fuertemente impregnado por profundas desigualdades de oportunidades, de activos y de resultados.

Gran parte de la literatura sobre el giro hacia la izquierda ha tratado sobre las diferentes izquierdas: socialdemócratas y populistas; carnívoros y vegetarianos, etcétera. Aquí hemos tratado de ver no sólo las variaciones relevantes, sino lo que creemos es el combustible común detrás de esta transformación de la política y de las políticas: una brecha creciente entre la expansión de la dinámica que democratiza y legitima las aspiraciones de consumo, movilidad y obtención de estatus (democracia, urbanización, logros educativos, exposición a patrones de consumo) y el paisaje congelado en lo que se refiere a las dinámicas necesarias para democratizar la capacidad de satisfacer las nuevas aspiraciones, extendidas y crecientes (estructura ocupacional, redistribución de activos, garantías de bienestar, redistribución de la renta).

En los últimos años, los pueblos latinoamericanos cuestionaron el experimento neoliberal. No decimos que se incrementó la protesta social en la región debido al fracaso total y completo del intento liberal de incorporación. Es precisamente debido a que en algunas áreas hubo avances (democracia electoral duradera, urbanización, educación y acceso a nuevas tecnologías de comunicación y sus efectos sobre la exposición a los patrones de consumo) que se hizo más notorio el fracaso en la democratización de oportunidades, ingresos y activos. Por esto decimos que la crisis de incorporación representa el límite del proyecto de modernización conservadora. La región seguirá siendo profundamente inestable en términos políticos, a menos que se enfrente esta crisis de incorporación mediante una redistribución más profunda del bienestar material y un acceso verdaderamente meritocrático a los canales de movilidad, garantizando la inclusión de sectores más amplios de la población latinoamericana. 


\section{Bibliografía}

Andrenacci, Luciano y Fabián Repetto, 2006, Universalismo, ciudadanía y Estado en la política social latinoamericana, Washington, BID-INDES, mimeo.

Arditi, Benjamín, 2008, “Arguments about the Left Turns in Latin America: A PostLiberal Politics?”, Latin American Research Review, vol. 43, núm. 3, pp. 59-81.

Banco Mundial, 2009, World Development Indicators, Washington, World Bank Electronic Resources Data Set.

Blofield, Merike y Juan Pablo Luna, 2011, "Public Opinion on Income Inequalities in Latin America", en Merike Blofield (ed.), The Great Gap: Inequality and the Politics of Redistribution in Latin America, University Park, Pennsylvania State University Press, pp. 147-181.

Castañeda, Jorge, 2006, “Latin America's Left Turn”, Foreign Affairs, vol. 85, núm. 3, mayo-junio.

Cecchini, Simone y Andras Uthoff, 2007, Reducción de la pobreza, tendencias demográficas, familias y mercado de trabajo en América Latina, Santiago de Chile, CEPAL, Serie Políticas Sociales, núm.136.

CEPAL, 2007, Panorama social de América Latina, Santiago de Chile, CEPAL.

Corrales, Javier, 2006, "The Backlash against Market Reforms and The Left in Latin America in the 2000s", en Jorge Domínguez y Michael Shifter (eds.), Constructing Democratic Governance in Latin America, Baltimore, Johns Hopkins University Press, pp. 1-24.

Cleary, Matthew, 2006, "Explaining the Left's Resurgence", en Journal of Democracy, vol. 17, núm. 4, pp. 35-49.

ECLAC, 2006, Shaping the Future of Social Protection. Access, Financing and Solidarity. Santiago de Chile, CEPAL.

Filgueira, Carlos, 1983, “To Educate or not to Educate: Is that the Question?", en ECLAC Review, núm. 21, pp. 57-80.

Filgueira, Carlos, 1981, "Consumption in the New Latin American Models", en ECLAC Review, núm. 15, pp. 71-110. 
Filgueira, Fernando, 1999, “Tipos de welfare y reformas sociales en América Latina: eficiencia, residualismo y ciudadanía estratificada", en M. A. Melo (ed.), Reforma do Estado e mudanca institucional no Brasil, Recife, Editora Massangana.

Filgueira, Fernando et al., 2005, Universalismo básico : una alternativa posible y necesaria para mejorar las condiciones de vida en América Latina, Montevideo, INDES.

Germani, Gino, 1962, Política y sociedad en una época de transición. De la sociedad tradicional a la sociedad de masas, Buenos Aires, Paidós.

Golbert, Laura, 2004, ¿Derecho a la inclusión o paz social? Plan Jefas y Jefes de Hogar Desocupados, Santiago de Chile, CEPAL, Serie Políticas Sociales núm. 84.

Heintz, Peter, 1964, Un Paradigma Sociológico del desarrollo, con especial referencia a América Latina, Buenos Aires, Instituto Torcuato Di Tella.

Kurtz, Marcus, 2004, “The Dilemmas of Democracy in the Open Economy: Lessons from Latin America", en World Politics, vol. 56, núm 2, pp. 262-302.

Lander, Edgardo, 2007, “Venezuela: logros y tensiones en los primeros ocho años del proceso de cambio", en Beatriz Stolowicz (coord.), Gobiernos de izquierda en América Latina. Un balance político, Bogotá, Aurora, pp. 39-76.

Lanzaro, Jorge, 2007, “La 'tercera ola' de las izquierdas latinoamericanas: entre el populismo y la socialdemocracia", en Encuentros Latinoamericanos, vol. 1, núm. 1, pp. 20-57.

Luna, Juan Pablo, 2007, Blossoming in the Desert: Is the Left Really Growing in Contemporary Latina America? Why? For How Long?, ponencia al seminario "Latin America's Left Turns?: Political Parties, Insurgent Movements, and Alternative Policies", University of British Columbia, Vancouver.

Moore, Barrington, 1966, The Social Origins of Dictatorship and Democracy, Boston, Beacon Press.

Orellana, Lorgio, 2006, Nacionalismo, populismo y régimen de acumulación en Bolivia. Hacia una caracterización del gobierno de Evo Morales, La Paz, CEDLA.

Panizza, Francisco, 2005, “The Social democratisation of the American Left", en Revista Europea de Estudios Latinoamericanos y del Caribe, núm. 79, pp. 95-103.

Polanyi, Karl, 1944, The Great Transformation, Boston, Beacon Press. 
Przeworski, Adam, Michael E. Alvarez, José Antonio Cheibub y Fernando Limongi, 2000, Democracy and Development: Political Institutions and Well-Being in the World, 1950-1990, Cambridge, Cambridge University Press.

Ramírez, Franklin y Analía Minteguiaga, 2007, “El nuevo tiempo del Estado. La política posneoliberal del correísmo", OSAL, Año VIII, núm. 22, pp. 87-103.

Reygadas, Luis y Fernando Filgueira, 2010, “Inequality and the Incorporation Crisis: The Left's Social Policy Toolkit”, en Maxwell Cameron y Eric Hershberg (eds.), Latin America's Left Turns: Politics, Policy E Trajectories of Change, Boulder, Lynne Rienner Publishers, pp. 171-191.

Roberts, Kenneth, 2007, “Latin's America Populist Revival”, en SAIS Review, vol. 27, núm. 1, pp. 3-15.

Roberts, Kenneth, 2008, “The Mobilization of Opposition to Economic Liberalization", en Annual Review of Political Science, 11, 327-349.

Rochlin, James, 2007, “Latin America's Left Turn and the New Strategic Landscape: The Case of Bolivia', en Third World Quarterly, vol. 28, núm. 7, pp. 1327-1342.

Robinson, William, 2008, "Transformative possibilities in Latin America", en Socialist Register, ano 2008, pp. 141-159.

Schamis, Hector, 2006, "Populism, Socialism, and Democratic Institutions", Journal of Democracy núm. 17, pp. 19-34.

Serrano Claudia, 2005, La política social en la globalización. Programas de protección en América Latina, Santiago de Chile, CEPAL (Serie Mujer y Desarrollo núm. 70).

Smith, Peter, 2004, "Cycles of Electoral Democracy in Latin America 1990-2000". Berkeley, Centre for Latin American Studies, University of Berkeley at California, Working Paper \#6.

Stefanoni, Pablo, 2006, "De la calle al palacio: los desafíos de la izquierda boliviana", Entre Voces, núm. 5, pp. 69-72.

Svalestuen, Guro, 2007, Un análisis del Plan de Atención Nacional a la Emergencia Social del Uruguay, Bergen, tesis de maestría, Universidad de Bergen, Departamento de Español y Estudios Latinoamericanos.

Tokman, Victor, 2007, Informalidad, Inseguridad y Cohesión Social en América Latina, Santiago de Chile, CEPAL (Serie Políticas Sociales, núm. 130). 
Waissbluth, Mario, 2006, La Reforma del Estado en Chile 1990-2005. De la confrontación al consenso, Santiago de Chile, Universidad de Chile.

Weyland, Kurt, 2009, “The Rise of Latin America's Two Lefts: Insights from Rentier State Theory", Comparative Politics, vol. 41, núm. 2, pp. 145-64.

Recibido el 30 de junio de 2011 우 Aceptado el 19 de diciembre de 2011 